Research

Open Access

\title{
Following severe injury, hypocholesterolemia improves with convalescence but persists with organ failure or onset of infection
}

\author{
C Michael Dunham ${ }^{1}$, Michael H Fealk² and Wilbur E Sever III² \\ ${ }^{1}$ Assistant Director, Trauma/Critical Care Services, St. Elizabeth Health Center, Youngstown, Ohio, USA \\ ${ }^{2}$ Trauma/Critical Care Services, St. Elizabeth Health Center, Youngstown, Ohio, USA
}

Correspondence: C Michael Dunham, Michael_Dunham@hmis.org

Received: 17 March 2003

Revisions requested: 13 June 2003

Revisions received: 18 August 2003

Accepted: 21 August 2003

Published: 1 October 2003
Critical Care 2003, 7:R145-R153 (DOI 10.1186/cc2382)

This article is online at http://ccforum.com/content/7/6/R145

(C) 2003 Dunham et al., licensee BioMed Central Ltd (Print ISSN 1364-8535; Online ISSN 1466-609X). This is an Open Access article: verbatim copying and redistribution of this article are permitted in all media for any purpose, provided this notice is preserved along with the article's original URL.

\begin{abstract}
Introduction Our primary objective was to determine the impact of traumatic injury, onset of infection, organ/metabolic dysfunction, and mortality on serum cholesterol.

Methods During 676 surgical intensive care unit (SICU) days, 28 ventilated trauma patients underwent daily measurement of white blood cell (WBC) count and differential, cholesterol, arterial oxygen tension/fractional inspired oxygen, bilirubin, glucose, creatinine, and bicarbonate. With the onset of infection, WBC response was considered positive if the WBC count was 16.0 or greater, immature neutrophils were $10 \%$ or greater, or WBC count increased by $20 \%$. Cholesterol response was considered positive if cholesterol decreased or failed to increase by $10 \%$.

Results Injury Severity Score was $30.6 \pm 8.6$ and there were 48 infections. Initial cholesterol was decreased $(119 \pm 44 \mathrm{mg} / \mathrm{dl})$ compared with expected values from a database $(201 \pm 17 \mathrm{mg} / \mathrm{dl}$; $P<0.0001)$. The 25 survivors had higher cholesterol at SICU discharge $(143 \pm 35 \mathrm{mg} / \mathrm{dl})$ relative to admission (112 $\pm 37 \mathrm{mg} / \mathrm{dl} ; P<0.0001)$. In the three patients who died, the admission cholesterol was $175 \pm 62 \mathrm{mg} / \mathrm{dl}$ and the cholesterol at death was $117 \pm 27 \mathrm{mg} / \mathrm{dl}$. The change in percentage of expected cholesterol (observed value divided by expected value) from admission to discharge was different for patients surviving $(16 \pm 19 \%)$ and dying $(-29 \pm 19 \% ; P=0.0005)$. With onset of infection, the WBC response was positive in $61 \%$ and cholesterol response was positive in $91 \%(P=0.001)$. Percentage of expected cholesterol was decreased with each system dysfunction: arterial oxygen tension/fractional inspired oxygen $<350$, creatinine $>2.0 \mathrm{mg} / \mathrm{dl}$, glucose $>120 \mathrm{mg} / \mathrm{dl}$, bilirubin $>2.5 \mathrm{mg} / \mathrm{dl}$, and bicarbonate $\geq 28$ or $\leq 23(P<0.01)$. Percentage of expected cholesterol decreased as the number of dysfunctions increased $(P=0.0001)$.

Conclusion Hypocholesterolemia is seen following severe injury. Convalescing patients (ready for SICU discharge) have improved cholesterol levels, whereas dying patients appear to have progressive hypocholesterolemia. Decreasing or fixed cholesterol levels suggest the development of infection or organ/metabolic dysfunction. Cholesterol responses are more sensitive for the onset of infection than are WBC responses. Sequential cholesterol monitoring is recommended for patients with severe trauma.
\end{abstract}

Keywords cholesterol, infection, injuries, mortality, multiple organ failure, wounds

$\mathrm{Cl}=$ confidence interval $\mathrm{CPI}=$ culture-positive infection; $\mathrm{FiO}_{2}=$ fractional inspired oxygen; $\mathrm{MOF}=$ multiple organ failure; $\mathrm{PaO}_{2}=$ arterial oxygen tension; SICU = surgical intensive care unit; $\mathrm{WBC}=$ white blood cell. 


\section{Introduction}

In 1994 Dunham and coworkers [1] demonstrated that patients with severe trauma had a sudden reduction in total serum cholesterol concentration. Hypocholesterolemia has been found in patients undergoing surgical interventions [2], and in those with multiple organ dysfunction syndrome [3-5] and burns [6]. There is also a suggestion that serum cholesterol correlates with organ failure and sepsis [1]. However, the use of serum cholesterol as a prognostic indicator of infection and multiple organ dysfunction syndrome, and as a biologic marker for resolution of systemic inflammation is less well defined. Proposed explanations for the development of hypocholesterolemia include downregulation of hepatic synthesis [5], dilutional effects with resuscitation [7], loss of apoproteins in burns after blister formation [6], and metabolic utilization $[5,8]$.

Hypocholesterolemia occurring with the development of infection was demonstrated during the 15-year period of the Kaiser Permanente study, conducted in 15000 healthy men and women [9]. Other authors have associated hypocholesterolemia with inflammatory states $[10,11]$. A 30\% or greater reduction in lipid and lipoprotein concentrations is known to occur in a variety of inflammatory states [11]. Interleukin-6 and tumor necrosis factor- $\alpha$ have been implicated as potent negative regulators of lipoprotein metabolism in vitro $[12,13]$ and in vivo $[14,15]$.

Fraunberger and coworkers [13] demonstrated a relationship between hypocholesterolemia and several disease states, as well as organ dysfunction. In patients with multiple organ dysfunction syndrome, a plasma cholesterol below $100 \mathrm{mg} / \mathrm{dl}$ was associated with increased mortality $(P<0.05)$. A decrease in plasma cholesterol was also associated with increased circulating levels of tumor necrosis factor.

The stimuli for the present study were our previous experience and the evolving literature. This study assessed four hypotheses: hypocholesterolemia is seen early after severe injury; hypocholesterolemia is improved at surgical intensive care unit (SICU) discharge in surviving patients as compared with cholesterol levels at admission; with the onset of infections, hypocholesterolemia is persistent or progressive; and hypocholesterolemia is associated with organ/metabolic dysfunction.

\section{Methods \\ Patients/design}

The Institutional Review Board for Investigation of Human Subjects approved this study.

All patients admitted to the trauma service at Saint Elizabeth Health Center in Youngstown, Ohio (a level I trauma center; under the care of CMD) had total serum cholesterol (cholesterol) measured as part of their routine morning laboratory
28 acutely injured patients with either blunt or penetrating traumatic injuries requiring 7 days or more of mechanical ventilation were studied. Data were collected during 676 consecutive days of SICU stay. Laboratory data were analyzed with a specific focus on cholesterol values and their relation to traumatic injury, onset of culture-positive infection (CPI), organ/metabolic dysfunction, and SICU discharge.

\section{Laboratory data}

Laboratory values that were monitored included white blood cell (WBC) count, WBC differential, cholesterol, arterial oxygen tension $\left(\mathrm{PaO}_{2}\right) /$ fractional inspired oxygen $\left(\mathrm{FiO}_{2}\right)$, total bilirubin, serum creatinine, serum bicarbonate, and serum glucose. The percentage of immature neutrophils was the sum of the percentage of bands, myelocytes, and metamyelocytes. Expected cholesterol values were based on comprehensive age- and sex-specific data from the general population [16]. SICU admission (postinjury) cholesterol was defined as the mean of morning cholesterol values on hospital days 1, 2, and 3 . It seemed that a mean value from the first 3 days, rather than a single-day point estimate, would more likely reflect the postinjury cholesterol response. During the SICU stay a mean cholesterol value was computed. SICU discharge cholesterol was defined as the mean of morning cholesterol values on the last 3 days of the SICU stay. The percentage of expected cholesterol was computed as the measured serum cholesterol divided by the expected cholesterol.

\section{Culture-positive infection}

CPI was defined as an SICU day in which there was clinical evidence for a new infection: two or more criteria for systemic inflammatory response syndrome met; bacterial growth on a culture medium; and need for antimicrobial therapy (initiated, modified, or continued). With the exception of bacteremia and vascular catheter infections, a CPI required the presence of polymorphonuclear neutrophils on Gram stain or cell analysis at the infection site. Vascular catheter infections had 100 bacterial colonies or more on semiquantitative culture. A diagnosis of pneumonia required moderate to abundant polymorphonuclear leukocytes on sputum Gram stain, moderate to abundant bacterial growth on culture medium, a decreasing $\mathrm{PaO}_{2} / \mathrm{FiO}_{2}$, and a new or progressive pulmonary infiltrate on chest $\mathrm{X}$-ray film.

\section{White blood cell response and cholesterol response at the time of a culture-positive infection}

Because infections typically evolve over a couple of days, a mean of WBC and cholesterol values before CPI and at the time of CPI were used, as opposed to using single-day point estimates. The WBC count, percentage of immature neutrophils, and cholesterol before a CPI were computed. These values were the means of the laboratory data for the 2 days before a CPI. The WBC count, percentage of immature neutrophils, and cholesterol at the time of a CPI were also computed. These values were the means of the laboratory data on 
the day of a $\mathrm{CPI}$ and the day after a $\mathrm{CPI}$. Before analyzing the WBC and cholesterol responses, we stipulated WBC and cholesterol changes or values that were thought to provide a clinical indication that an infection might have developed. The following a priori criteria were applied, with no post-hoc effort to retrofit and adjust the values. At the time of a $\mathrm{CPI}$, the WBC response was considered positive when mean WBC count was $\geq 16.0 \times 10^{3} \mathrm{cells} / \mu \mathrm{l}$; mean immature neutrophils were $\geq 10 \%$; or there was an increase in the mean WBC count by $\geq 20 \%$ relative to the mean count before a CPI. At the time of a CPI, a positive cholesterol response was defined as the failure of the mean cholesterol to increase by more than $10 \%$ relative to the mean cholesterol before a CPI. In other words, cholesterol increased by $10 \%$ or less, or it decreased. A 10\% level was selected because this effect size is commonly used in causal analysis and statistical assessment of data. The rate of a positive WBC response and the rate of a positive cholesterol response at the time of $\mathrm{CPI}$ were calculated.

\section{Organ/metabolic dysfunction analysis}

$\mathrm{PaO}_{2} / \mathrm{FiO}_{2}$, serum bilirubin, serum glucose, serum creatinine, and serum bicarbonate were assessed for significant relationships with percentage of expected cholesterol.

\section{Statistical analysis}

Statistical analysis was performed using the SAS System for Windows, release 6.11 (SAS Institute Inc., Cary, NC, USA). Continuous data are represented as the mean and standard deviation. Paired Student's $t$-tests were used to compare expected cholesterol with immediate postinjury cholesterol and the mean cholesterol during the SICU stay. A paired Student's $t$-test was used to compare admission cholesterol with discharge cholesterol. A Fisher's exact test was used to compare the rate of positive cholesterol response with the rate of positive WBC response during onset of CPIs. Correlation coefficient analysis was utilized to assess the relationship between two continuous variables. Multiple regression analysis was utilized to assess the influence of two or more independent variables on a dependent variable. $P<0.05$ was considered statistically significant.

\section{Results}

\section{Subject characteristics}

Twenty males and eight females met the study criteria. Four patients had penetrating injuries and twenty-four had sustained blunt injuries. The age was $39.1 \pm 13$ years, Injury Severity Score was 30.6 \pm 8.6 , and CPI per patient was 1.7 (range 0-5). Death occurred in three patients (Table 1).

\section{Surgical intensive care unit hypocholesterolemia}

During the entire SICU course, the observed mean cholesterol for the 28 patients was decreased $(132 \pm 33 \mathrm{mg} / \mathrm{dl}$, $95 \%$ confidence interval [Cl] 119-145) as compared with the expected value $(201 \pm 17 \mathrm{mg} / \mathrm{dl}, 95 \% \mathrm{Cl} 194-208$; $P<0.0001)$. This represents a $34.3 \%$ reduction. SICU
Table 1

Subject characteristics and cholesterol values

\begin{tabular}{|c|c|c|c|c|c|c|c|}
\hline \multirow[b]{2}{*}{ Patient } & \multirow[b]{2}{*}{ Age } & \multirow[b]{2}{*}{ Male } & \multicolumn{3}{|c|}{$\begin{array}{l}\text { CPIs during } \\
\text { SICU stay }\end{array}$} & \multicolumn{2}{|c|}{ Cholesterol (mg/dl) } \\
\hline & & & ISS & $(n)$ & Survived & Expected & Mean \pm SD \\
\hline$A$ & 22 & No & 41 & 2 & Yes & 183 & $134 \pm 33$ \\
\hline B & 33 & Yes & 42 & 3 & Yes & 201 & $100 \pm 25$ \\
\hline $\mathrm{C}$ & 24 & No & 34 & 1 & No & 183 & $98 \pm 12$ \\
\hline D & 35 & Yes & 27 & 2 & No & 201 & $187 \pm 30$ \\
\hline$E$ & 45 & Yes & 10 & 1 & No & 211 & $116 \pm 35$ \\
\hline $\mathrm{F}$ & 37 & No & 16 & 5 & Yes & 189 & $116 \pm 20$ \\
\hline $\mathrm{G}$ & 36 & Yes & 30 & 2 & Yes & 201 & $137 \pm 19$ \\
\hline $\mathrm{H}$ & 33 & Yes & 43 & 4 & Yes & 201 & $93 \pm 12$ \\
\hline 1 & 38 & Yes & 35 & 2 & Yes & 201 & $123 \pm 19$ \\
\hline J & 58 & Yes & 38 & 4 & Yes & 216 & $191 \pm 28$ \\
\hline $\mathrm{K}$ & 51 & Yes & 35 & 1 & Yes & 216 & $97 \pm 5$ \\
\hline L & 61 & No & 34 & 1 & Yes & 235 & $102 \pm 9$ \\
\hline$M$ & 50 & No & 26 & 2 & Yes & 228 & $137 \pm 15$ \\
\hline $\mathrm{N}$ & 45 & Yes & 25 & 2 & Yes & 211 & $155 \pm 29$ \\
\hline $\mathrm{O}$ & 55 & Yes & 17 & 3 & Yes & 216 & $133 \pm 19$ \\
\hline$P$ & 40 & Yes & 19 & 2 & Yes & 211 & $166 \pm 14$ \\
\hline Q & 21 & No & 36 & 1 & Yes & 183 & $120 \pm 40$ \\
\hline $\mathrm{R}$ & 49 & Yes & 5 & 0 & Yes & 211 & $82 \pm 06$ \\
\hline$S$ & 25 & Yes & 36 & 2 & Yes & 180 & $195 \pm 28$ \\
\hline $\mathrm{T}$ & 38 & No & 57 & 1 & Yes & 189 & $106 \pm 17$ \\
\hline$U$ & 67 & Yes & 14 & 1 & Yes & 217 & $118 \pm 11$ \\
\hline V & 24 & No & 34 & 2 & Yes & 183 & $145 \pm 12$ \\
\hline W & 38 & Yes & 42 & 1 & Yes & 201 & $192 \pm 25$ \\
\hline$x$ & 43 & Yes & 24 & 1 & Yes & 211 & $113 \pm 27$ \\
\hline Y & 16 & Yes & 26 & 0 & Yes & 158 & $131 \pm 53$ \\
\hline Z & 38 & Yes & 34 & 0 & Yes & 201 & $91 \pm 9$ \\
\hline$A A$ & 43 & Yes & 35 & 1 & Yes & 211 & $165 \pm 39$ \\
\hline BB & 29 & Yes & 29 & 1 & Yes & 180 & $153 \pm 35$ \\
\hline
\end{tabular}

CPI, culture-positive infection; ISS, Injury Severity Score; SD, standard deviation; SICU, surgical intensive care unit.

hypocholesterolemia is described in Fig. 1. The percentage of expected cholesterol was $67 \pm 21 \%$ (range 20-140\%).

\section{Immediate postinjury hypocholesterolemia}

The SICU admission (postinjury) cholesterol was decreased ( $n=28 ; 119 \pm 44 \mathrm{mg} / \mathrm{dl}, 95 \% \mathrm{Cl} 102-136)$ as compared with the expected cholesterol $(201 \pm 17 \mathrm{mg} / \mathrm{dl}, 95 \% \mathrm{Cl}$ 194-208; $P=0.0001)$. The postinjury cholesterol was $59.4 \%$ of the expected cholesterol. Fig. 1 demonstrates the reduction in postinjury cholesterol in two patients. 


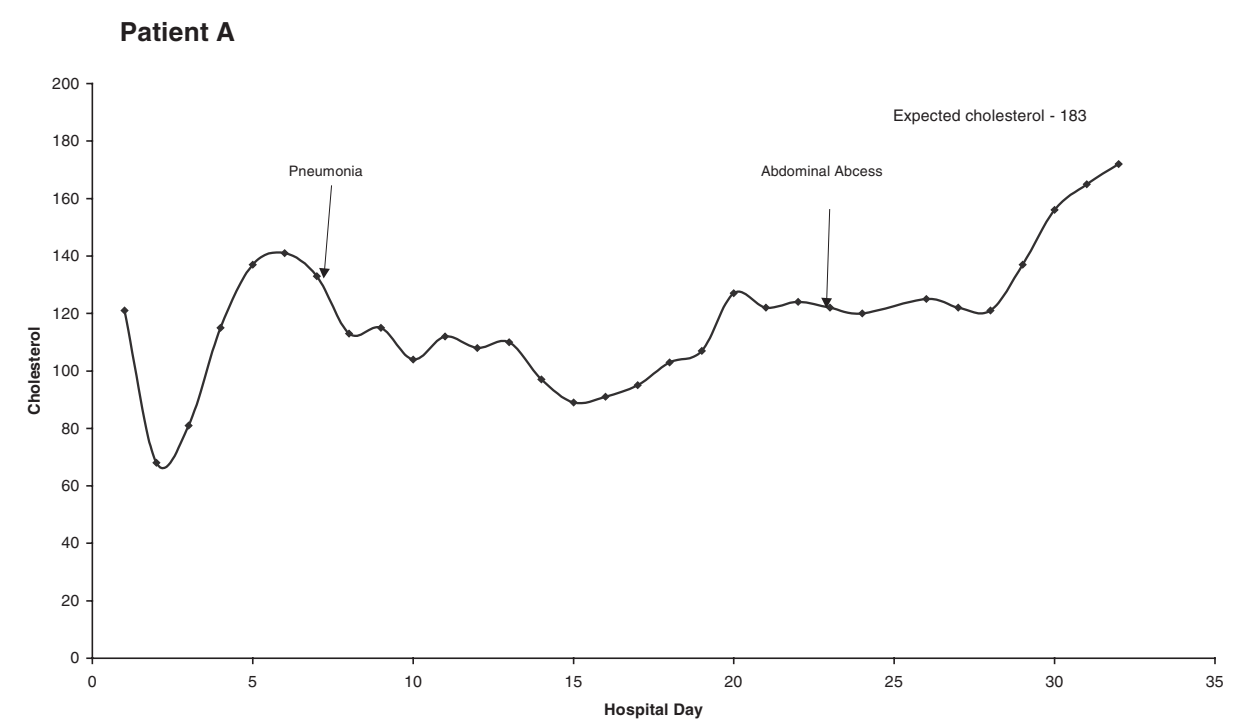

Patient B

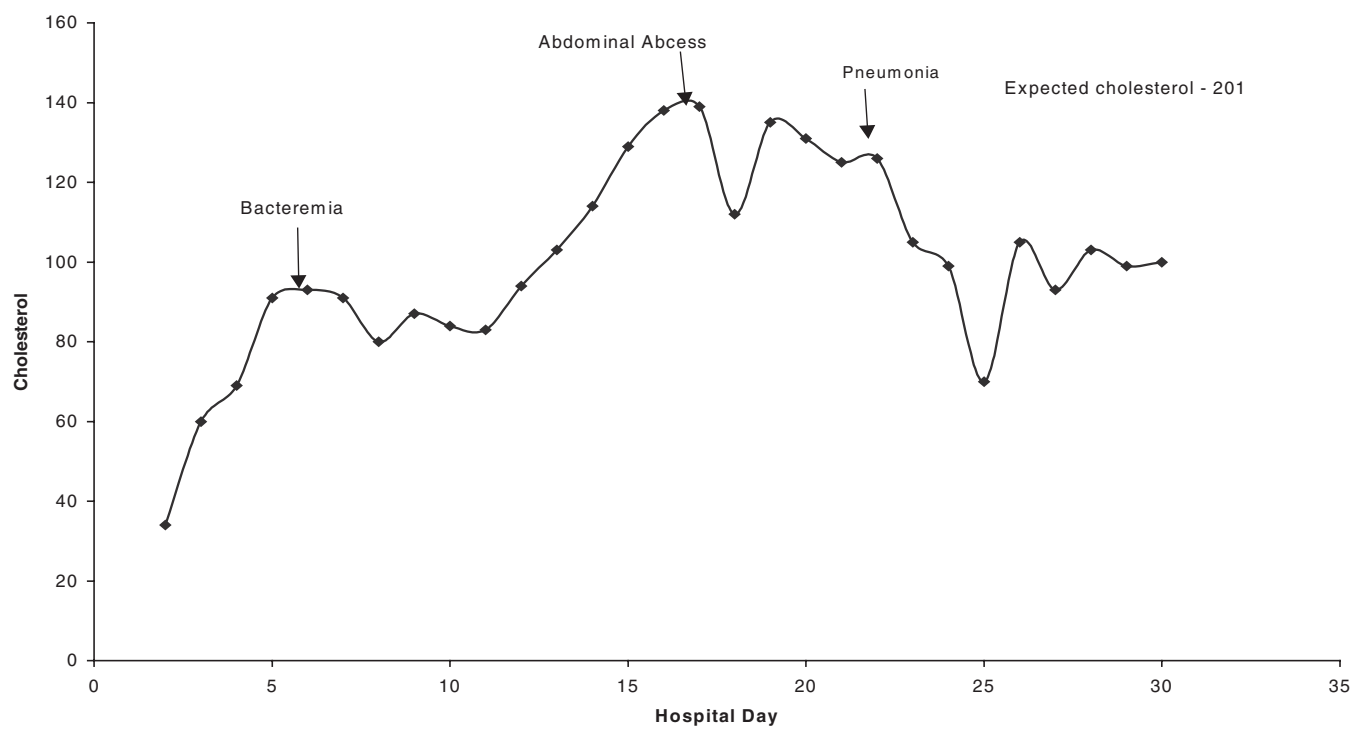

The graphs for patients A and B (see Table 1) demonstrate postinjury hypocholesterolemia, persistent hypocholesterolemia with culture-positive infection, and partial resolution of hypocholesterolemia at discharge from the surgical intensive care unit.

\section{Comparison of total serum cholesterol at surgical intensive care unit admission and discharge}

For the 25 surviving patients, the cholesterol at SICU discharge was significantly increased $(143 \pm 35 \mathrm{mg} / \mathrm{dl}) \mathrm{com}-$ pared with admission cholesterol $(112 \pm 37 \mathrm{mg} / \mathrm{dl}$; $P<0.0001)$. The SICU discharge value was $27.7 \%$ greater than the admission level. Post-hoc analysis revealed a power of $97 \%$ for means testing. The $95 \% \mathrm{Cl}$ for SICU discharge cholesterol was 128-157 and for SICU admission it was 97-127. An increase in cholesterol from SICU admission to discharge is demonstrated in Fig. 1. For the three patients who died, the cholesterol was $117 \pm 27 \mathrm{mg} / \mathrm{dl}$ at SICU dis- charge value was $33.1 \%$ lower than the admission level. There was a significant difference in the discharge minus admission cholesterol values between the patients who died $(-58 \pm 40 \mathrm{mg} / \mathrm{dl})$ and those who survived $(31 \pm 36 \mathrm{mg} / \mathrm{dl}$; $P=0.0005)$. There was a significant difference in the discharge minus admission percentage of expected cholesterol values between the patients who died $(-29 \pm 19 \%)$ and those who survived (16 $\pm 19 \% ; P=0.0005)$.

\section{White blood cell and cholesterol responses on days of culture-positive infection}

During the 676 days of SICU care, the WBC count was $16.3 \pm 7.1 \times 10^{3} \mathrm{cells} / \mu \mathrm{l} \quad\left(\right.$ range $3.9-48.2 \times 10^{3} \mathrm{cells} / \mu \mathrm{l}$ ), 
immature neutrophils comprised $3.3 \pm 5.4 \%$ (range 0-45\%), and cholesterol was $132 \pm 38 \mathrm{mg} / \mathrm{dl}$ (range $34-248 \mathrm{mg} / \mathrm{dl}$ ). Forty-eight CPIs occurred during the SICU course: 32 pneumonia, four bacteremia, three abdominal abscess/peritonitis, two central nervous system infections, four vascular catheter infections, and three severe wound infections. Three patients were without infection and 25 had one to five infections (Table 1). Mean cholesterol and WBC count values before the $\mathrm{CPI}$ and at the time of the $\mathrm{CPI}$ were computed: cholesterol $138 \pm 39 \mathrm{mg} / \mathrm{dl}$ and $131 \pm 37 \mathrm{mg} / \mathrm{dl}$, respectively $(P=0.26)$; and WBC count $16.3 \pm 6.1 \times 10^{3} \mathrm{cells} / \mu \mathrm{l}$ and $16.6 \pm 7.3 \times 10^{3}$ cells $/ \mu$ l, respectively $(P=0.78)$. In $46 \mathrm{CPls}$ a WBC differential was also available; immature neutrophils comprised $3.9 \pm 6.7 \%$ and $4.8 \pm 7.1 \%$ before and the time of the $\mathrm{CPI}$, respectively $(P=0.38)$.

Cholesterol data were available for all $48 \mathrm{CPIs}$. A positive cholesterol response occurred in 43 (89.6\%). Specific cholesterol values at the time of the $\mathrm{CPI}$ relative to those before the CPI were categorized: in five CPIs there was an increase by $>10 \%(10.4 \%)$; in $17 \mathrm{CPls}$ there was a decrease by $>10 \%$ (35.4\%); and there was no substantial increase or decrease in $26 \mathrm{CPIs}$ (54.2\%). WBC count data were available for 47 of the CPls. Specific WBC counts at the time of the $\mathrm{CPI}$ relative to those before the CPI were noted: in $17 \mathrm{CPls}$ there was an increase by $>10 \%(36.2 \%)$; in $16 \mathrm{CPls}$ there was a decrease by $>10 \%$ (34.0\%); and there was no substantial increase or decrease in 14 (29.8\%). Among the $46 \mathrm{CPls}$ in which WBC count, percentage immature neutrophils, and cholesterol data were available, the WBC response was positive in $28(60.9 \%)$ and the cholesterol response was positive in 42 (91.3\%; odds ratio 6.8; $P=0.001)$. A positive WBC response or positive cholesterol response was present in 45 out of $46 \mathrm{CPls}$ (97.8\%).

\section{Days of persistent hypocholesterolemia following onset of culture-positive infections}

With the onset of a $\mathrm{CPI}$, the cholesterol value decreased below the preinfection level over the next $5.1 \pm 3.7$ days (range 0-14 days, total days 240). The 240 days accounted for $35.5 \%$ of the total SICU days of observation. The time required for the cholesterol to improve by more than $10 \%$, relative to the lowest postinfection value, was $5.0 \pm 3.2$ days (total days 237, range 1-14 days). The 237 days accounted for $35.1 \%$ of the total SICU days of observation. Fig. 1 shows the persistent hypocholesterolemia associated with $\mathrm{CPI}$.

\section{Relationships between hypocholesterolemia and organ/metabolic dysfunction}

Significant relationships were found between percentage of expected cholesterol and organ/metabolic dysfunction (creatinine, bilirubin, bicarbonate, $\mathrm{PaO}_{2} / \mathrm{FiO}_{2}$, and glucose), and these are described in Table 2. The percentage of expected cholesterol was independently associated with creatinine, bilirubin, bicarbonate, and $\mathrm{PaO}_{2} / \mathrm{FiO}_{2}(r=0.32 ; P=0.001)$. An organ/metabolic dysfunction score was computed (creatinine
Table 2

\begin{tabular}{|c|c|c|c|}
\hline Condition & $\begin{array}{l}\% \text { Cholesterol } \\
\text { without condition }\end{array}$ & $\begin{array}{l}\% \text { Cholesterol } \\
\text { with condition }\end{array}$ & $P$ \\
\hline Creatinine $>2.0 \mathrm{mg} / \mathrm{dl}$ & $68 \pm 21$ & $55 \pm 13$ & 0.0001 \\
\hline Bilirubin $>2.5 \mathrm{mg} / \mathrm{dl}$ & $68 \pm 21$ & $60 \pm 21$ & 0.0006 \\
\hline $\begin{array}{l}\text { Bicarbonate } \geq 28 \text { or } \\
\leq 23 \mathrm{mmol} / / \mathrm{l}\end{array}$ & $71 \pm 22$ & $63 \pm 19$ & 0.0001 \\
\hline $\mathrm{PaO}_{2} / \mathrm{FiO}_{2}<350$ & $74 \pm 21$ & $65 \pm 20$ & 0.0001 \\
\hline Glucose $>120 \mathrm{mg} / \mathrm{dl}$ & $69 \pm 19$ & $65 \pm 23$ & 0.009 \\
\hline
\end{tabular}

$\%$ Cholesterol is the cholesterol value as a percentage of expected cholesterol. Values are expressed as mean \pm standard deviation. $\mathrm{FiO}_{2}$, fractional inspired oxygen; $\mathrm{PaO}_{2}$, arterial oxygen tension.

$>2.0 \mathrm{mg} / \mathrm{dl}$ [score 0 or 1$]+$ bilirubin $>2.5 \mathrm{mg} / \mathrm{dl}[0$ or 1$]+$ bicarbonate $\leq 23$ or $\geq 28 \mathrm{mmol} / \mathrm{l}[0$ or 1$]+\mathrm{PaO}_{2} / \mathrm{FiO}_{2}<350$ [0 or 1] + glucose $>120 \mathrm{mg} / \mathrm{dl}$ [0 or 1], yielding a total score in the range $0-5)$. Percentage of expected cholesterol progressively decreased as the number of organ/metabolic dysfunctions increased ( $n=676 ; r=-0.30 ; P=0.0001$; Table 3 ). The WBC count exhibited a relative increase as the number of organ/metabolic dysfunctions increased $(r=0.17$; $P=0.0001$ ). The percentage immature neutrophils increased as the number of organ/metabolic dysfunctions increased $(r=0.25 ; P=0.0001)$. The number of organ/metabolic dysfunctions was independently associated with percentage of expected cholesterol, WBC count, and percentage immature neutrophils $(r=0.36 ; P=0.001)$. Multiple organ failure (MOF) was defined as the presence of two or more organ/metabolic dysfunctions. Observations with MOF were associated with a lower percentage of expected cholesterol $(n=482$; $64 \pm 20 \%)$ than were observations without MOF $(n=194$; $75 \pm 20 \% ; P=0.0001)$.

The organ/metabolic dysfunctions were greater in the patients who died $(n=49 ; 2.5 \pm 0.7)$ than in those who survived $(n=627 ; 1.9 \pm 1.0 ; P=0.0001)$. The rate of MOF was increased in the patients who died (95.9\%) as compared with the rate in those who survived (69.4\%; odds ratio 10.4 ; $P=0.0001)$.

\section{Discussion}

The present study is the largest description of sequential cholesterol monitoring in critically injured patients. The primary findings of the study are that hypocholesterolemia is present following critical injury (marked decrease in SICU admission cholesterol values compared with expected values); clinical convalescence is associated with an improvement in hypocholesterolemia (increase in SICU discharge cholesterol values compared with SICU admission values); patients who die appear to have a progressive deterioration in serum cholesterol; and cholesterol levels fluctuate during the SICU 


\begin{tabular}{|c|c|c|c|c|c|}
\hline Score & Observations & $\begin{array}{c}\% \mathrm{WBC} \\
\text { as immature } \\
\text { neutrophils }\end{array}$ & $\begin{array}{c}\text { WBC } \\
\% \\
\text { Cholesterol* }^{*}\end{array}$ & $\begin{array}{c}\left(\times 10^{3}\right. \\
\text { cells } / \mu \mathrm{l})\end{array}$ & $\begin{array}{c}\% \text { Immature } \\
\text { neutrophils }\end{array}$ \\
\hline 0 & 60 & 8.9 & $81 \pm 15$ & $16.4 \pm 7.3$ & $1.4 \pm 2.6$ \\
\hline 1 & 134 & 19.8 & $72 \pm 21$ & $15.1 \pm 6.4$ & $2.5 \pm 5.4$ \\
\hline 2 & 281 & 41.6 & $67 \pm 21$ & $15.2 \pm 6.3$ & $2.8 \pm 4.4$ \\
\hline 3 & 167 & 24.7 & $62 \pm 20$ & $17.8 \pm 7.9$ & $4.4 \pm 6.0$ \\
\hline 4 & 33 & 4.9 & $51 \pm 14$ & $21.6 \pm 8.0$ & $9.3 \pm 9.0$ \\
\hline \multirow[t]{2}{*}{5} & 1 & 0.1 & $54 \pm 0.0$ & $32.9 \pm 0.0$ & $5.0 \pm 0.0$ \\
\hline & & & $P=0.0001$ & $P=0.0001$ & $P=0.0001$ \\
\hline
\end{tabular}

*Percent cholesterol is the observed value as a percentage of the expected value. Values are mean and standard deviation.

course. During the SICU course, the percentage of expected cholesterol varied inversely with organ dysfunction. With the onset of SICU infections, hypocholesterolemia either worsens (serum cholesterol decreases) or persists (serum cholesterol does not increase or decrease). Previous studies have typically been static in their analysis, relying on single cholesterol values that do not reflect the dynamics of the daily care and course of severely injured patients.

Immediately after injury a reduction in cholesterol compared with expected values was apparent. Expected cholesterol values were used for comparison because the preinjury values in the patients studied were not available. The cholesterol value before trauma in these unselected patients was considered to be the average value in a general population of healthy people. The expected cholesterol values were obtained from age- and sex-based data produced by the nationally recognized National Health and Nutrition Examination Surveys [16]. These values have been corroborated in a survey that included 60502 people throughout North America [17]. The expected cholesterol levels have also been validated in a study that included 4600 persons [18]. All of the patients in the present study had serious injuries, as demonstrated by the need for mechanical ventilation for 7 days or longer, elevated Injury Severity Scores, a high rate of $\mathrm{CPI}$, and the notable mortality rate.

Soon after the introduction of a reliable assay for serum cholesterol in 1926, reports associated hypocholesterolemia with 'disease' [11]. Lower cholesterol levels were observed during the acute phase response concomitant with infection, surgical procedures, burns, and malignancy [10]. After operative intervention, cholesterol values may decrease by as much as $55 \%$ [7]. Although low lipid and lipoprotein levels have clearly been demonstrated in acutely ill patients, the prognostic
Patients with a new infection typically have a decrease in cholesterol or persistent hypocholesterolemia. A total of 48 serious CPIs were encountered in the 28 patients studied. Infections were varied and included pneumonia, bacteremia, abdominal abscess and peritonitis, central nervous system infection, vascular catheter infection, and deep, serious wound infections. All infections were associated with systemic and regional manifestations.

A decrease in cholesterol or persistence of hypocholesterolemia was more commonly associated with the development of a CPI than with the expected leukocyte response. The WBC count and differential at the time of infection did not consistently increase or decrease. Although most clinicians consider an increment in WBC or left-shift to be associated with the presence of infection, a positive WBC response was present in a much smaller percentage of CPIs in comparison with the higher percentage of CPls with a positive cholesterol response. Virtually all CPIs had a positive WBC and/or cholesterol response. Cholesterol values remained below the preinfection values for nearly 1 week and accounted for one-third of total SICU days. Cholesterol values required almost 1 week to increase substantially relative to the post-CPI nadir level. These data suggest that persistent or progressive hypocholesterolemia may be a more sensitive indicator of the onset of infection than is WBC response.

Cioffi and coworkers [19] reviewed the complex array of leukocyte responses following injury. Changes in leukocyte number and function can be associated with infection, sepsis, or the initial injury. Toutouzas and coworkers [20] documented the difficulty in discerning whether leukocytosis is associated with the injury per se or with infectious complications in patients undergoing postinjury splenectomy. Rovlias and Kotsou [21], in a recent report, indicated that leukocyto- 
sis is common in patients with severe brain injury. The findings in these reports support the notion that WBC responses are not predictive of infection.

In one ICU based study, Gordon and coworkers [10] noted that patients with clinical and/or laboratory evidence of infection had significantly lower mean high-density lipoprotein cholesterol concentrations. In another study of 111 critically ill patients, Gordon and coworkers [11] demonstrated a relationship between the degree of inflammation and the extent of hypocholesterolemia. Studies conducted both in humans and in nonhuman primates demonstrate an association between hypocholesterolemia and the release of endotoxin and cytokine mediators during sepsis [7]. When cholesterol values do not increase, the clinician should suspect possible infection in critically injured or ill patients.

Typically, organ/metabolic dysfunction scores reflect the degree of patient illness severity. In the present study, organ/metabolic dysfunction scores were derived from an evaluation of daily bicarbonate, bilirubin, creatinine, glucose, and $\mathrm{PaO}_{2} / \mathrm{FiO}_{2}$. The Acute Physiology and Chronic Health Evaluation III score [22], Simplified Acute Physiology Score [23], Multiple Organ Dysfunction Score [24], and Sequential Organ Failure Assessment Score [25] are recognized illness severity scoring systems and include variables that are similar to the five system components used in the present study: $\mathrm{PaO}_{2} / \mathrm{FiO}_{2}$ [22-25], acid-base balance [22,23], bilirubin [22-25], glucose [22], and creatinine [22,24,25]. The trauma patient MOFs described by Cryer and coworkers [26] and by Dunham and colleagues [27] also include the system components used in the present study: $\mathrm{PaO}_{2} / \mathrm{FiO}_{2}$ [26,27], acid-base balance [27], bilirubin [26], glucose [27], and creatinine $[26,27]$. Patients who died had a higher organ/metabolic score and rate of MOF than did the survivors. This further suggests the clinical relevance of the methodology used to describe organ/metabolic dysfunction in the present study.

Two other investigations have documented an association between hypocholesterolemia and organ failure [4,11]. Of relevance is that researchers have found cholesterol to be decreased in critically ill surgical patients with decreased hepatic protein synthesis [5]. Additionally, cholesterol during the first week after injury has been inversely associated with the number of ventilator days and hospital duration of stay [1]. These findings are consonant with our study findings that cholesterol is inversely related to organ dysfunction.

In the present study, the percentage of expected cholesterol values was inversely associated with the five organ/metabolic dysfunctions as well as with the derived score values. The number of organ/metabolic dysfunctions was also related to the WBC count and percentage of immature neutrophils. However, the correlation was greater with the percentage of expected cholesterol. These observations support the notion that organ/metabolic dysfunction described in the study is related to systemic inflammation. The independent relationship between organ/metabolic dysfunction and percentage of expected cholesterol, WBC count, and percentage immature neutrophils is also consistent with the thesis that cholesterol levels indicate that other inflammatory signals may be inciting homeostatic perturbations. The patients with MOF had a significantly lower percentage of expected cholesterol values than did those without MOF. These findings suggest that changes in hypocholesterolemia mirror the clinical course of critically injured patients.

Hypocholesterolemia was improved in the convalescing patients. In the survivors the cholesterol values at SICU discharge were significantly increased as compared with the admission values. Although the number of patients studied was relatively small, the power of the test was well within the range for difference of means testing in related samples. Furthermore, the lack of overlap between the 95\% upper limit for the admission value and the 95\% lower limit for the discharge value enhances the validity that the means of the two groups are different. In the three patients who died the cholesterol levels at the time of death were decreased compared with their SICU admission levels. However, the number of patients is too small for this observation to be conclusive. Gordon and coworkers [10] described decreased cholesterol values in patients requiring transfer to the SICU. Giovannini and coworkers [5] also found an increased frequency of hypocholesterolemia among patients with moderate to critical surgical illness requiring admission to the SICU. In summary, the present study indicates that cholesterol levels typically increase as patients convalesce and approach discharge from the SICU. On the other hand, patients who die appear to have a progressive decrement in cholesterol values.

There are study weaknesses that should be considered in future investigations. Fluid administration and dilution were not assessed for their impact on cholesterol levels. The amounts and types of lipid administered to the study patients may have been variable and might have influenced cholesterol values. However, routine enteral and parenteral nutritional support protocols were used in all patients. None of the patients received propofol. Total serum cholesterol values were performed each morning. Because no study patient was from an interhospital transfer, the times from injury to admission were similar. However, the time from injury to the following morning might have varied. The impact of this variation on cholesterol values was not considered. Future studies should consider the influence of the volume of fluid, and the amounts and types of lipids administered each day on serum cholesterol. Also, investigators may need to obtain cholesterol values at precise intervals relative to the time of injury. A study that includes a larger number of dying patients is necessary to determine whether patients who die have progressive hypocholesterolemia. 


\section{Key messages}

- Convalescing critically injured patients have an improvement in postinjury hypocholesterolemia

- Dying patients appear to have progressive hypocholesterolemia

- Patients with a new infection typically have a decrease in cholesterol or persistent hypocholesterolemia findings that are more sensitive for infection than are expected WBC responses

- Hypocholesterolemia is associated with organ/ metabolic dysfunction

- Daily cholesterol monitoring during the SICU course of critically injured patients may be shown in future studies to enhance patient outcome

\section{Conclusion}

This study is unique in that serum cholesterol values were sequentially monitored in critically injured patients during their SICU course. The convalescing, critically injured patients had a significant increment in cholesterol levels compared with the hypocholesterolemia that was observed initially following severe trauma. Patients who die appear to have a progressive decrement in serum cholesterol. A decrease in serum cholesterol or persistent hypocholesterolemia also suggests the onset of a new, serious infection. In contrast, WBC responses were less consistent and less sensitive in predicting the onset of infection. A decrement in cholesterol also indicates a progression in organ failure. Conversely, an increase in cholesterol suggests that organ failure is resolving. These data support the notion that serial serum cholesterol values parallel clinical improvement or deterioration in critically ill trauma patients. Future studies may prove that sequential cholesterol monitoring during the SICU course of critically injured patients will lead to more timely interventions and enhance patient outcomes.

\section{Competing interests}

None declared.

\section{Acknowledgement}

A pilot study of the first 14 patients was presented at the 61 st Annual Meeting of the American Association for the Surgery of Trauma, 26-28 September 2002, Orlando, Florida.

\section{References}

1. Dunham CM, Frankenfield D, Belzberg H, Wiles CE III, Cushing B, Grant Z: Inflammatory markers: superior predictors of adverse outcome in blunt trauma patients? Crit Care Med 1994, 22: 667-672.

2. Lindh A, Lindholm M, Rossner S: Intralipid disappearance in critically ill patients. Crit Care Med 1986, 14:476-480.

3. Fraunberger P, Nagel D, Walli AK, Seidel D: Serum cholesterol and mortality in patients with multiple organ failure. Crit Care
4. Lopez-Martinez J, Sanchez-Castilla M, Garcia-de-Lorenzo A: Hypocholesterolemia in critically ill patients. Intensive Care Med 2000, 26:259-260.

5. Giovannini I, Boldrini G, Chiarla C, Giuliante F, Vellone M, Nuzzo G: Pathophysiologic correlates of hypocholesterolemia in critically ill surgical patients. Intensive Care Med 1999, 25:748751.

6. Coombes EJ, Shakespeare PG, Batstone GF: Lipoprotein changes after burn injury in man. J Trauma 1980, 20:971-975.

7. Sun X, Oberlander D, Huang J, Weissman C: Fluid resuscitation, nutritional support, and cholesterol in critically ill postsurgical patients. J Clin Anesth 1998, 10:302-308.

8. Gui D, Spada PL, De Gaetano A, Pacelli F: Hypocholesterolemia and risk of death in the critically ill surgical patient. Intensive Care Med 1996, 22:790-794.

9. Iribarren C, Jacobs DR Jr, Sidney S, Claxton AJ, Feingold KR: Cohort study of serum total cholesterol and in-hospital incidence of infectious diseases. Epidemiol Infect 1998, 121:335347.

10. Gordon BR, Parker TS, Levine DM, Saal SD, Wang JC, Sloan BJ, Barie PS, Rubin AL: Low lipid concentrations in critical illness: implications for preventing and treating endotoxemia. Crit Care Med 1996, 24:584-589.

11. Gordon BR, Parker TS, Levine DM, Saal SD, Wang JC, Sloan BJ, Barie PS, Rubin AL: Relationship of hypolipidemia to cytokine concentrations and outcomes in critically ill surgical patients. Crit Care Med 2001, 29:1563-1568.

12. Ettinger WH, Varma VK, Sorci-Thomas M, Parks JS, Sigmon RC, Smith TK, Verdery RB: Cytokines decrease apolipoprotein accumulation in medium from Hep G2 cells. Arterioscler Thromb 1994, 14:8-13.

13. Fraunberger $P$, Schaefer $S$, Werdan K, Walli AK, Seidel D: Reduction of circulating cholesterol and apolipoprotein levels during sepsis. Clin Chem Lab Med 1999, 37:357-362.

14. Spriggs DR, Sherman ML, Michie $H$, Arthur KA, Imamura K, Wilmore D, Frei E III, Kufe DW: Recombinant human tumor necrosis factor administered as a 24-hour intravenous infusion. A phase I and pharmacologic study. I Natl Cancer Inst 1988, 80:1039-1044.

15. van Gameren MM, Willemse PH, Mulder NH, Limburg PC, Groen $H J$, Vellenga $E$, de Vries EG: Effects of recombinant human interleukin- 6 in cancer patients: a phase I-II study. Blood 1994, 84:1434-1441.

16. Centers for Disease Control and Prevention: Data from the National Center for Health Statistics. Third National Health and Nutrition Examination Survey, 1988-1994, NHANES III Examination Data File (CD-ROM). Public Use Data File Documentation Number 76200. Hyattsville, MD: Centers for Disease Control and Prevention; 1996.

17. Kuske TT, Feldman EB: Hyperlipoproteinemia, atherosclerosis risk, and dietary management. Arch Intern Med 1987, 147:357360 .

18. Burke GL, Sprafka JM, Folsom AR, Hahn LP, Luepker RV, Blackburn $\mathrm{H}$ : Trends in serum cholesterol levels from 1980 to 1987. The Minnesota Heart Survey. N Engl J Med 1991, 324:941946.

19. Cioffi WG, Burleson DG, Pruitt BA Jr: Leukocyte responses to injury. Arch Surg 1993, 128:1260-1267.

20. Toutouzas KG, Velmahos GC, Kaminski A, Chan L, Demetriades D: Leukocytosis after posttraumatic splenectomy: a physiologic event or sign of sepsis? Arch Surg 2002, 137: 924-928.

21. Rovlias A, Kotsou S: The blood leukocyte count and its prognostic significance in severe head injury. Surg Neurol 2001, 55:190-196.

22. Knaus WA, Wagner DP, Draper EA, Zimmerman JE, Bergner M, Bastos PG, Sirio CA, Murphy DJ, Lotring T, Damiamo A: The APACHE III prognostic system. Risk prediction of hospital mortality for critically ill hospitalized adults. Chest 1991, 100: 1619-1636.

23. Le Gall JR, Lemeshow S, Saulnier F: A new Simplified Acute Physiology Score (SAPS II) based on a European/North American multicenter study. JAMA 1993, 270:2957-2963.

24. Marshall JC, Cook DJ, Christou NV, Bernard GR, Sprung CL, Sibbald WJ: Multiple organ dysfunction score: a reliable descriptor of a complex clinical outcome. Crit Care Med 1995, 23:1638-1652. 
25. Antonelli M, Moreno R, Vincent JL, Sprung CL, Mendoca A, Passariello M, Riccioni L, Osborn J: Application of SOFA score to trauma patients. Sequential Organ Failure Assessment. Intensive Care Med 1999, 25:389-394.

26. Cryer HG, Leong K, McArthur DL, Demetriades D, Bongard FS, Fleming AW, Hiatt JR, Kraus JF: Multiple organ failure: by the time you predict it, it's already there. J Trauma 1999, 46:597604.

27. Dunham CM, Damiano AM, Wiles CE, Cushing BM: Post-traumatic multiple organ dysfunction syndrome-infection is an uncommon antecedent risk factor. Injury 1995, 26:373-378. 